\title{
Prevalence and clinical association of the presence of anti-neutrophilic cytoplasmic antibody in systemic sclerosis
}

\author{
Ajanee Mahakkanukrauh, Siraphop Suwannaroj, Ratanavadee Nanagara, Chingching Foocharoen
}

Division of Allergy-Immunology-Rheumatology, Department of Medicine, Khon Kaen University, Khon Kaen, Thailand

Submitted: 7 January 2019; Accepted: 21 April 2019

Online publication: 31 January 2020

Arch Med Sci 2021; 17 (6): 1696-1705

DOI: https://doi.org/10.5114/aoms.2019.85172

Copyright $\odot 2019$ Termedia \& Banach

\section{Abstract}

Introduction: Anti-neutrophilic cytoplasmic antibody (ANCA) has been reported in systemic sclerosis (SSC). Some clinical features of SSc can also be presented with ANCA-associated vasculitis. Objectives were to determine the prevalence and clinical associations with ANCA among Thais with SSC.

Material and methods: A cross-sectional study of Thai adult SSc patients was conducted. According to the sample size calculation, 185 patients were included. Clinical and laboratory tests for serology and others for evaluation of the clinical association with ANCA were done simultaneously on the study date.

Results: The female to male ratio was $2: 1$. The majority had the diffuse SSc subset $(71.2 \%)$. The respective prevalence of having a) at least 1 serological test for ANCA (viz., perinuclear ANCA, cytoplasmic ANCA, anti-myeloperoxidase, or anti-proteinase3), b) positive for either p-ANCA or c-ANCA, c) positive for either anti-MPO or anti-PR3, d) p-ANCA and anti-MPO and e) c-ANCA and anti-PR3 was $21.6 \%(95 \% \mathrm{Cl}: 15.9-28.3), 11.9 \%(95 \% \mathrm{Cl}: 7.6-17.4)$ and $13.0 \%(95 \% \mathrm{Cl}: 8.5-18.7)$ and $1 \%(95 \% \mathrm{Cl}: 0.1-3.9)$. By multivariate analysis, the erythrocyte sedimentation rate elevation was significantly associated with the presence of the antibody $(\mathrm{OR}=11.36,95 \% \mathrm{Cl}: 1.44-83.65)$, while elevation of high sensitivity cardiac troponin-T (hs-cTnT) was significantly associated with the presence of either p-ANCA or c-ANCA (OR $=4.25$, $95 \% \mathrm{Cl}: 1.41-15.34)$. None of the patients had clinical features of systemic vasculitis.

Conclusions: Around one-fifth of SSc patients have detectible ANCA without any features of vasculitis. The presence of ANCA is associated with inflammation and myocardial injury. ANCA is not antibody specific for vasculitis in SSC.

Key words: systemic sclerosis, scleroderma, vasculitis, anti-neutrophilic cytoplasmic antibody.

\section{Introduction}

Systemic sclerosis (SSc) or scleroderma is a connective tissue disease for which skin tightness is the hallmark. The disease is classified into two major subsets: limited cutaneous systemic sclerosis (ICSSC) and diffuse cutaneous systemic sclerosis (dcSSc) [1]. Fibrosis is a predominant pathological finding in scleroderma and it presents not only in the skin but also in the internal organs such as the kidneys, lungs, heart, and intestines [2-6].

\author{
Corresponding author: \\ Dr. Chingching Foocharoen \\ Division of Allergy- \\ Immunology- \\ Rheumatology \\ Department \\ of Medicine \\ Faculty of Medicine \\ Khon Kaen University \\ 40002 Khon Kaen \\ Thailand \\ Phone: 66-43-363-746, \\ 66-43-363-664 \\ E-mail: fching@kku.ac.th
}


The condition of an SSc patient who has features of connective tissue disease apart from SSc is called SSc overlap syndrome. Systemic sclerosis overlap vasculitis is rare [7] and reports are limited to mostly case reports of anti-neutrophilic cytoplasmic antibody (ANCA) associated vasculitis [8]. Nearly $80 \%$ of cases of SSc overlap vasculitis are CREST syndrome, which is also reported in those who have no cutaneous tightness (viz. systemic sclerosis sine scleroderma) [7].

ANCA is subclassified into two immunofluorescence patterns - cytoplasmic ANCA (c-ANCA) and perinuclear ANCA (p-ANCA). Atypical ANCA (a-ANCA) is used when the fluorescence pattern is incompatible with the two classical patterns. c-ANCA is mainly directed against proteinase- 3 , and if C-ANCA is indicated, the presence of anti-proteinase3 (anti-PR3) is usually used as a confirmatory test. p-ANCA is mainly directed against myeloperoxidase and anti-myeloperoxidase (anti-MPO) is tested for confirmation in case of the presence of p-ANCA $[9,10]$.

The prevalence of ANCA in SSC is reported to be between $2.4 \%$ and $11.7 \%$ [11-15]. ANCA is commonly revealed in ICSSC or CREST syndrome [7]. The most common manifestation in SSc was renal involvement, particularly crescentic glomerulonephritis [7]. Other clinical features include massive alveolar hemorrhage [14], normotensive renal failure [15], pulmonary renal syndrome [7], pulmonary hypertension [7], skin purpura [7], digital ulcers [7], severe digital ischemia [16], neuropathy [7], and necrotizing angiitis of the small vessels in multiple internal organs [15]. The data indicate a poor prognosis in patients who had pulmonary-renal syndrome associated with ANCA and the condition has been reported in both dcSSC and ICSSc [7].

Digital ischemia is a well-known feature of vasculopathy in SSc, and particularly IcSSc. There is a report of severe digital ischemia with histologically proven vasculitis in IcSSC positive for ANCA. According to the literature, in cases of refractory digital ischemia, SSc overlap with ANCA-associated vasculitis should be considered [16].

The presence of ANCA in other connective tissue disease has been reported and the clinical association with the presence of the antibody has been investigated [17-24]. However, there has been no study on the association between ANCA and the clinical presentations in SSC and the outcome of SSc patients positive for ANCA. In daily practice, ANCA is not a routine laboratory test but it will be tested for in cases of clinically suspected small vessel vasculitis, particularly rapidly progressive glomerulonephritis and alveolar hemorrhage. Some clinical features of SSc that are likely features of small vessel vasculitis (i.e., digital ulcer, proteinuria with renal failure, and neuropathy) have never been investigated for exclusion of small vessel vasculitis. Moreover, most Thai SSc patients have the dcSSc subset, which is different from Caucasians and some Asians. Our objectives were to (a) determine the prevalence of ANCA among Thais with SSC and (b) find out the clinical associations with its occurrence.

\section{Material and methods}

We conducted a cross-sectional study among Thai adult SSc patients, followed up between November 1, 2016 and November 30, 2017, at the Scleroderma Clinic, Srinagarind Hospital, Khon Kaen University, Khon Kaen, Thailand. All of the patients were over 18, had a diagnosis of SSC based on the American College of Rheumatology criteria and/or fulfilled the classification criteria of systemic sclerosis by ACR/EULAR 2013 [25]. Systemic sclerosis was classified as the limited or diffuse type as per LeRoy et al. [26].

All eligible patients underwent a clinical assessment and blood test for all of the following factors that could be clinically associated with ANCA on the same date (date of enrollment).

- Routine laboratory tests for SSc assessment including complete blood count, renal function and urinalysis.

- Serology including anti-topoisomerase I antibody (ATA), anti-centromere antibody (ACA), ANCA both p-ANCA and c-ANCA, anti-MPO and anti-PR3.

- Blood test for high-sensitivity cardiac troponin-T (hs-cTnT), complement level (C3 and C4) and inflammatory markers including erythrocyte sedimentation rate (ESR) and C-reactive protein (CRP).

\section{Operational definitions}

Anti-MPO and anti-PR3 were tested using the EUROIMMUN AG (Lübeck, Germany) by the Euroline immunoblot immunoglobulin G (IgG) technique. ANCA was tested using the EUROIMMUN AG (Lübeck, Germany) by indirect immunofluorescence testing and classified into 2 patterns (p-ANCA and c-ANCA). Antibodies with borderline and weakly positive signal intensities which had a titer less than $1: 10$ were considered negative in the current study.

The onset of disease was considerate the date of first symptoms. The definition of pulmonary fibrosis was fulfilled when interstitial fibrosis was detected by either chest radiography or high resolution computed tomography (HRCT). Pulmonary arterial hypertension (PAH) was defined by a mean pulmonary arterial pressure $\geq 25 \mathrm{~mm} \mathrm{Hg}$ and a pulmonary capillary wedge pressure $<15 \mathrm{~mm} \mathrm{Hg}$ from right heart catheterization [27]. 
Esophageal involvement was defined when any esophageal symptoms of SSc such as esophageal dysphagia, heartburn, or reflux symptoms were revealed. Stomach involvement was defined by the symptom of early satiety or vomiting. Intestinal involvement was determined by the symptoms of diarrhea, bloating, malabsorption, constipation, ileus or pseudo-intestinal obstruction. Renal impairment was indicated when serum creatinine $(\mathrm{Cr})$ was $>1.4 \mathrm{mg} / \mathrm{dl}$. The definition of proteinuria was fulfilled when 24 -h urine protein was $>0.5$ g/day. Neuropathy was defined when the patient reported symptoms of neuropathy and the neuropathy was confirmed by electrodiagnostic study. Anemia was confirmed when $\mathrm{Hb}<12.0 \mathrm{~g} / \mathrm{dl}$ in females and $<13.0$ in males. Baseline comorbid conditions were determined according to the modified version of Elixhauser's methodology [28].

\section{Sample size calculation}

Sample size calculation was based on the prevalence of the presence of ANCA in SSc patients which was the primary objective of the study. The sample was applied as per the previous prevalence of the presence of ANCA in the literature review. The prevalence of SSc in the general population size calculation was $1: 100,000$ and the previous prevalence of the presence of ANCA in SSc was $3-11 \%[11-15,29]$. According to the formula of Daniel (1999) [30], we recruited 185 subjects to the study. The patients of the study were selected by random sampling from the Scleroderma Clinic.

\section{Ethics approval and consent to participate}

The study was designed by the authors and approved by the Human Research Ethics Committee of Khon Kaen University as per the Helsinki Declaration and the Good Clinical Practice Guidelines

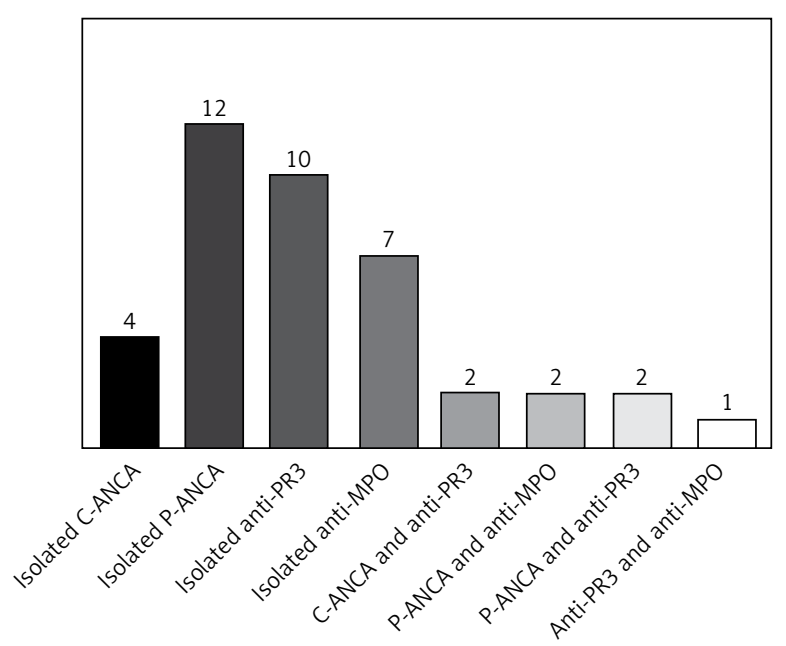

Figure 1. The number of patients in each serological test
(HE591375). All eligible patients signed informed consent before enrollment. The sponsor had no role in the study.

\section{Statistical analysis}

The prevalence of the presence of ANCA with the $95 \%$ confidence interval $(\mathrm{Cl})$ was calculated. The odds ratio with $95 \% \mathrm{Cl}$ was used to assess which clinical characteristics were associated with the presence of ANCA. Variables with $p<0.1$ were entered into a multivariate logistic regression model. $P<0.05$ was defined as statistically significant. The data were analyzed using STATA version 11.2 (StataCorp., College Station, TX, USA).

\section{Results}

A total of 185 SSc patients were included with a female to male ratio of $2: 1$, of whom the majority had the dcSSc (71.2\%). The mean age was $58.0 \pm 10.1$ years (range: $19.7-84.5$ ). The median duration of disease was 6.4 years (interquartile range (IQR): 2.9-10.1).

Among the 185 patients, 40 presented at least 1 serological test positive for ANCA ( $p$-ANCA, c-ANCA, anti-MPO or anti-PR3) with the prevalence of $21.6 \%(95 \% \mathrm{Cl}: 15.9-28.3)$. Positive for p-ANCA was the most common type of ANCA detection (12 patients; 30\%), followed by positive for anti-PR3 (10 patients; 25\%) and positive for antiMPO (7 patients; 17.5\%), respectively (Figure 1). Among those who had a serological test positive for ANCA, 22 were positive for either p-ANCA or c-ANCA, and 24 were positive for either anti-MPO or anti-PR3 with the respective prevalence of 11.9\% (95\% Cl: $7.6-17.4)$ and $13.0 \%(95 \% \mathrm{Cl}: 8.5-$ 18.7). The presence of $p$-ANCA and anti-MPO was revealed in 2 patients with the prevalence of $1 \%$ (95\% Cl: 0.1-3.9) and the presence of C-ANCA and anti-PR3 was found in 2 patients with the prevalence of $1 \%(95 \% \mathrm{Cl}: 0.1-3.9)$. None of these patients had clinical features of systemic vasculitis.

The respective presence of ATA, elevated ESR, and weight loss at the onset was associated with the presence of at least 1 serological test positive for ANCA according to the univariate analysis, but only ESR elevation was significantly associated with the presence of the antibody with an odds ratio (OR) of 11.36 (95\% Cl: 1.44-83.65). The other SSc manifestations and clinical features indicative of small vessel vasculitis (viz., digital ulcer, proteinuria and neuropathy) were not associated with the presence of the antibodies (Table I). Among those who had proteinuria during follow-up, 9 patients had urine protein $>0.5 \mathrm{~g} /$ day, in 5 of whom it was due to diabetic nephropathy and in 1 to a scleroderma renal crisis. The remaining patients had non-nephrotic range proteinuria and 


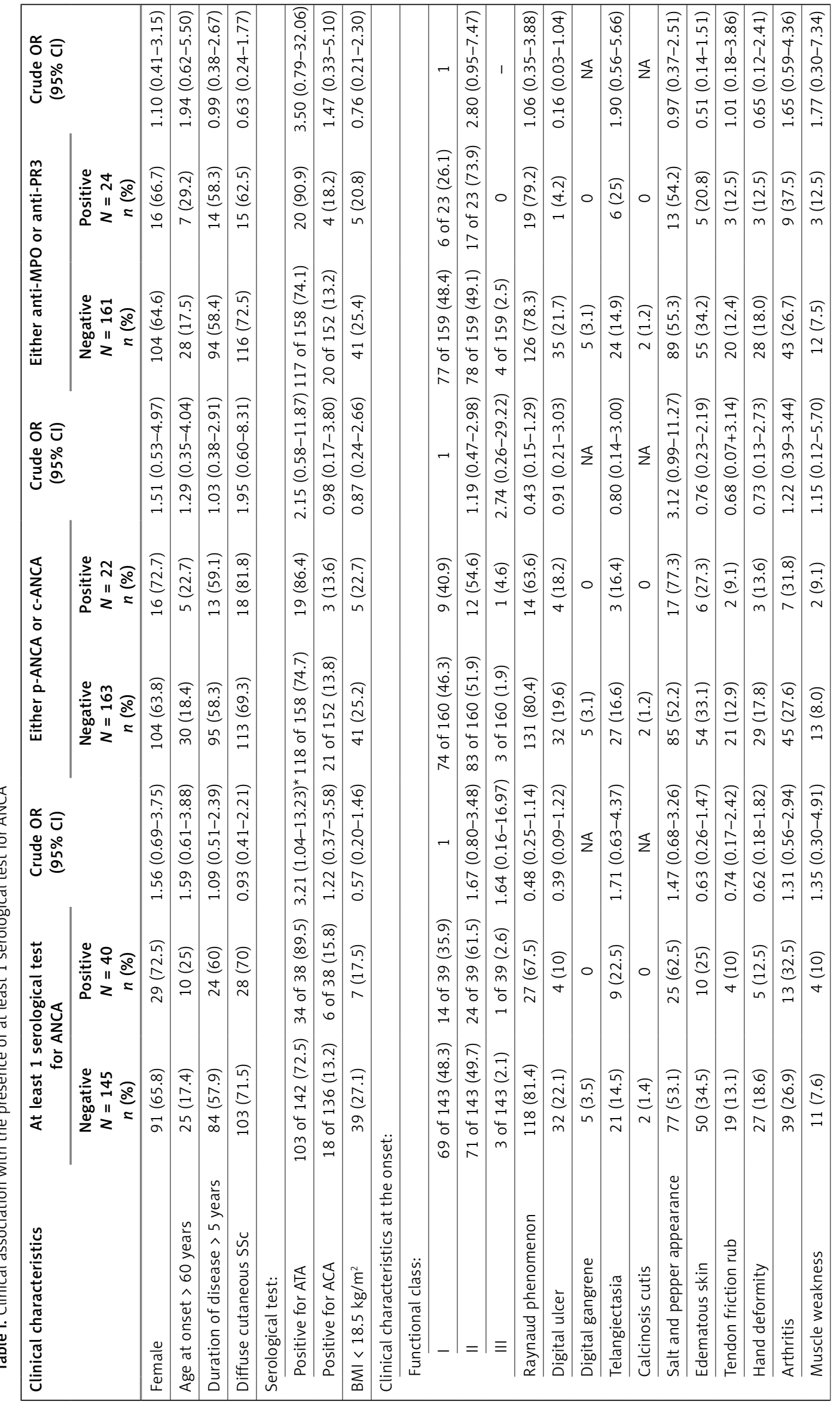




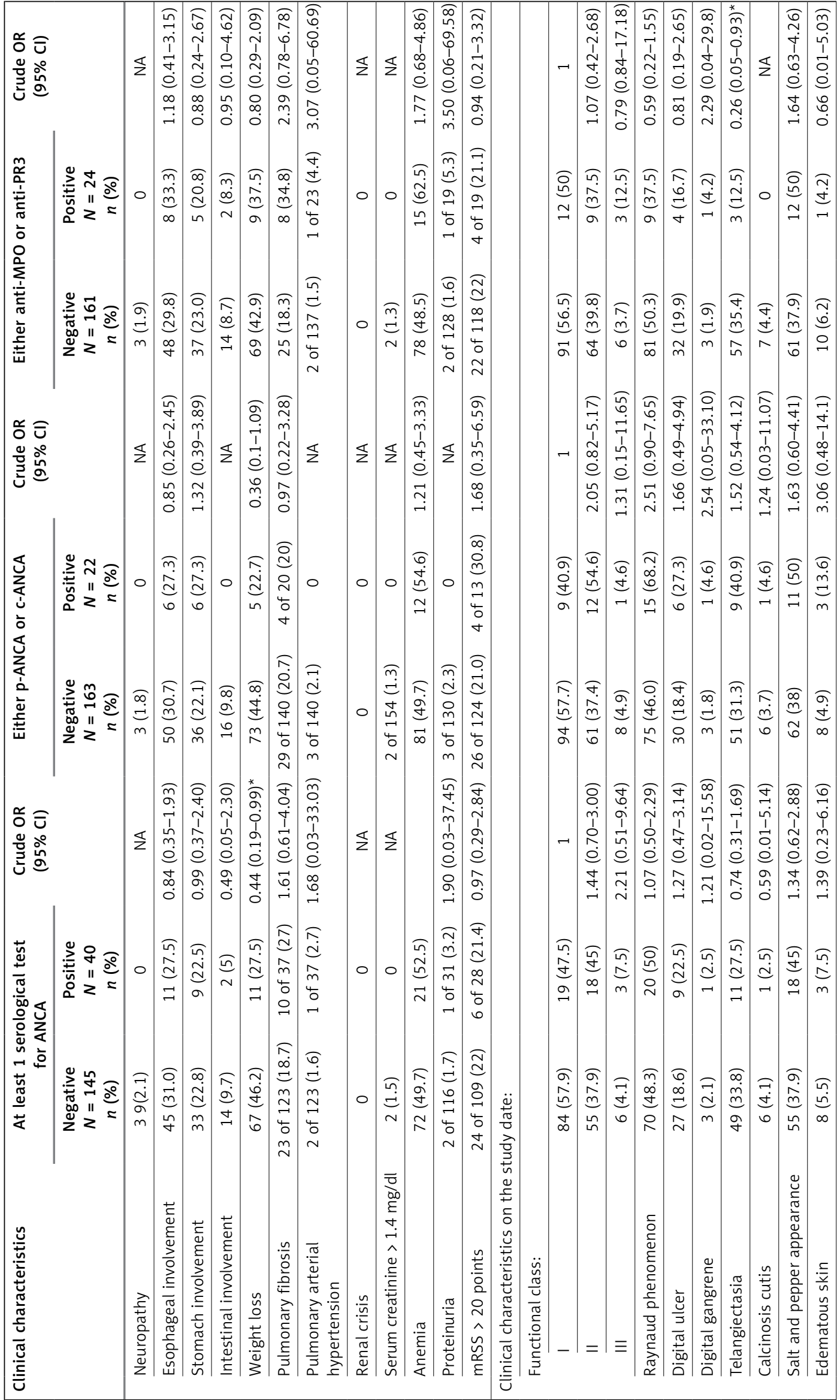




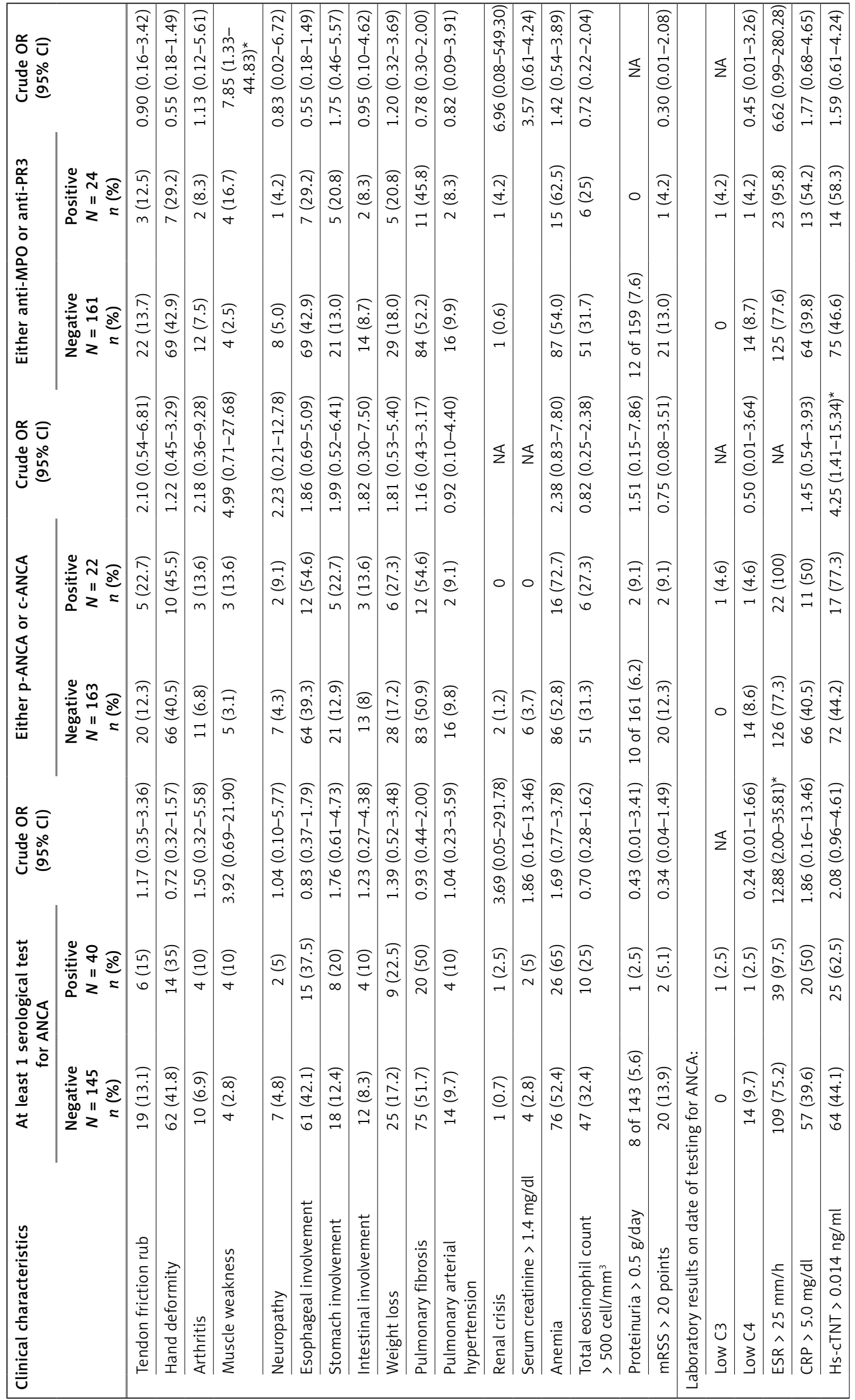




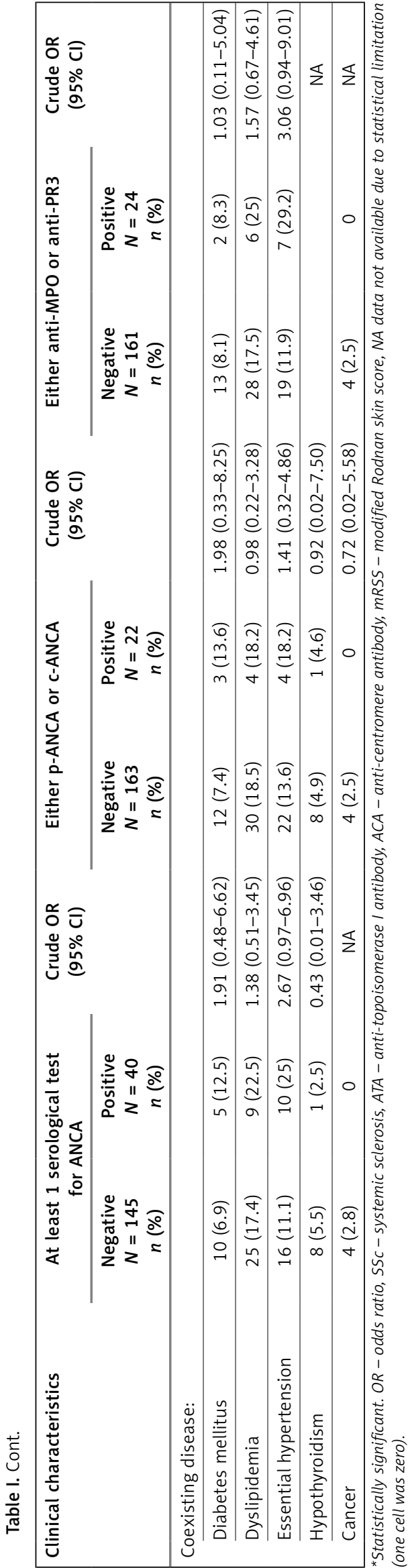

no urine sediment. None of the patients underwent kidney biopsy. The median proteinuria was 1.26 g/day (IQR: 0.71-2.35).

Telangiectasia and muscle weakness at follow-up was significantly associated with the presence of either anti-MPO or anti-PR3; according to both univariate and logistic regression analysis $(\mathrm{OR}=0.25,95 \% \mathrm{Cl}: 0.07-0.93$ and $\mathrm{OR}=7.97$, $95 \% \mathrm{Cl}: 1.75-36.42$, respectively). Elevated level of hs-cTnT was the only variable significantly associated with the presence of either p-ANCA or c-ANCA among our SSc patients (OR $=4.25$, 95\% Cl: 1.41-15.34) (Table I).

After subgroup analysis, there was no clinical difference between the patients who were positive for p-ANCA and anti-MPO and also between those who were positive for C-ANCA and anti-PR3.

\section{Discussion}

The prevalence of ANCA positivity among our SSc patients is comparable to previous reports (i.e., $2.4-11.7 \%$ ) [11-15, 31] Although the dcSSc subset is common among Thai patients, the prevalence of ANCA positivity was not different between dcSSc and IcSSc subsets, like the result from the previous study that revealed ANCA positivity in both dcSSc and IcSSc subsets [7, 13, 32]. According to our analysis, erythrocyte sedimentation rate elevation, rise of hs-cTnT, telangiectasia and muscle weakness were associated with the presence of ANCA in Thai SSc, whereas the study of Rho et al. found an association between anti-topoisomerase I antibody and the occurrence of ANCA-associated vasculitis [32]. However, most of the studies did not find a clinical association with the presence of ANCA (Table II).

According to the multivariate analysis, hs-cTnT was the parameter associated with the presence of either p-ANCA or c-ANCA. hs-cTnT is a cardiac marker of myocardial injury and it has a high sensitivity and negative predictive value for diagnosis of acute myocardial injury [33]. Of note, $48 \%$ of our patients had elevated hs-cTnT and none had clinically suggested myocardial infarction or other causes of rise of hs-cTnT. A large cohort from Italy showed that the prevalence of positivity for ANCA among SSc patients was 5.8\%, among whom $65 \%$ were positive for p-ANCA. The patients who were ANCA positive had a significantly higher incidence of myocardial inflammation and mortality rate than those who were ANCA negative [34]. The study, however, was not published, so the patients' clinical characteristics and details of the study have not been fully reported. According to another study, $37 \%$ of SSc patients in WHO functional class (FC) I had elevated hs-cTnT without any cardiac symptoms. The authors found that there was no correlation between inflammatory 
Table II. Comparison of prevalence and factors associated with ANCA positivity in SSc patients

\begin{tabular}{|c|c|c|c|c|c|}
\hline \multirow[t]{2}{*}{ Author(s) } & \multirow[t]{2}{*}{$N$} & \multirow[t]{2}{*}{ Ethnicity } & \multirow[t]{2}{*}{ Prevalence of ANCA positivity } & \multicolumn{2}{|c|}{ Clinical association } \\
\hline & & & & $\begin{array}{l}\text { p-ANCA or } \\
\text { c-ANCA }\end{array}$ & $\begin{array}{l}\text { Anti-MPO or } \\
\text { anti-PR3 }\end{array}$ \\
\hline \multirow[t]{2}{*}{ Our study } & \multirow[t]{2}{*}{185} & \multirow[t]{2}{*}{ Thai } & \multirow{2}{*}{$\begin{array}{c}\text { At least } 1 \text { test positive } 21.6 \% \\
\text { Either p-ANCA or c-ANCA } 11.9 \% \\
\text { Either anti-MPO or anti-PR3 } 13 \% \\
\text { p-ANCA } 6.5 \% \\
\text { c-ANCA } 2.2 \% \\
\text { Anti-MPO } 3.8 \% \\
\text { Anti-PR3 } 5.4 \% \\
\text { Both p-ANCA and anti-MPO 1\% } \\
\text { Both c-ANCA and anti-MPO } 1 \%\end{array}$} & \multicolumn{2}{|c|}{$\begin{array}{l}\text { Erythrocyte sedimentation rate } \\
\quad \text { elevation }(\mathrm{OR}=11.36)\end{array}$} \\
\hline & & & & $\begin{array}{l}\text { High-sensitivity } \\
\text { cardiac } \\
\text { troponin- } \\
\text { elevation } \\
(\mathrm{OR}=4.25)\end{array}$ & $\begin{array}{l}\text { Telangiectasia } \\
(\mathrm{OR}=0.25) \text { and } \\
\text { muscle weakness } \\
(\mathrm{OR}=7.97)\end{array}$ \\
\hline $\begin{array}{l}\text { Derrett-Smith, } \\
\text { et al. [31] }\end{array}$ & 2,200 & English & $\begin{array}{c}\text { Either anti-MPO or anti-PR3 } 0.4 \% \\
\text { ( } 8 \text { cases), of which } 1 \text { was } p-A N C A \\
\text { positive }\end{array}$ & - & $\begin{array}{l}\text { GN ( } 6 \text { of } 8 \text { cases), } \\
\text { skin ( } 4 \text { of } 8 \text { cases), } \\
\text { peripheral neuropathy } \\
\text { ( } 2 \text { of } 8 \text { cases })\end{array}$ \\
\hline $\begin{array}{l}\text { Ruffatti, } \\
\text { et al. [13] }\end{array}$ & 115 & Italian & $\begin{array}{c}\text { At least } 1 \text { test positive } 7 \% \\
\text { p-ANCA 4.3\% } \\
\text { Anti-MPO (medium to high titer) } \\
0.8 \% \\
\text { Anti-PR3 (medium to high titer) } \\
3.5 \% \\
\text { Both p-ANCA and anti-MPO 0.8\% } \\
\text { Both p-ANCA and anti-PR3 3.5\% }\end{array}$ & $\begin{array}{l}\text { No significant } \\
\quad \text { clinical } \\
\text { association }\end{array}$ & $\begin{array}{c}\text { No significant clinical } \\
\text { association }\end{array}$ \\
\hline $\begin{array}{l}\text { Akimoto, } \\
\text { et al. [14] }\end{array}$ & 77 & Japanese & $\begin{array}{c}\text { p-ANCA } 11.7 \% \\
\text { c-ANCA } 0 \% \\
\text { Anti-MPO } 22.1 \% \\
\text { Both p-ANCA and anti-MPO } 9.1 \%\end{array}$ & None & $\begin{array}{l}1 \text { who was positive } \\
\text { for both p-ANCA } \\
\text { and anti-MPO had } \\
\text { systemic small vessel } \\
\text { necrotizing angiitis }\end{array}$ \\
\hline $\begin{array}{l}\text { Caramaschi, } \\
\text { et al. [12] }\end{array}$ & 62 & Italian & $\begin{array}{c}\text { Anti-MPO weakly positive } 1.6 \% \\
\text { Anti-PR3 } 1.6 \%\end{array}$ & - & None \\
\hline $\begin{array}{l}\text { Rho, } \\
\text { et al. [32] }\end{array}$ & 50 & Korean & $\begin{array}{l}\text { Anti-MPO 72\% } \\
\text { Anti-PR3 24\% }\end{array}$ & \multicolumn{2}{|c|}{$\begin{array}{c}\text { Anti-topoisomerase associated with } \\
\text { the occurrence of ANCA-associated } \\
\text { vasculitis }(O R=3.1)\end{array}$} \\
\hline $\begin{array}{l}\text { Merkel, } \\
\text { et al. [11] }\end{array}$ & 45 & American & $\begin{array}{c}\text { Atypical ANCA } 15.6 \% \\
\text { Either p-ANCA or c-ANCA 0\% } \\
\text { Either anti-PR3 or anti-MPO 0\% }\end{array}$ & - & - \\
\hline $\begin{array}{l}\text { Liang, } \\
\text { et al. [7] }\end{array}$ & 14 & American & $\begin{array}{c}\text { Both p-ANCA and anti-MPO } 71.4 \% \\
\text { p-ANCA, anti-MPO and anti-PR3 } \\
7.1 \%\end{array}$ & \multicolumn{2}{|c|}{$\begin{array}{l}\text { Classical clinical vasculitis included } \\
\text { glomerulonephritis, pulmonary-renal } \\
\text { syndrome, skin purpura and neuropathy }\end{array}$} \\
\hline
\end{tabular}

markers and the elevation of hs-cTnT [35]. The primary mechanism of myocardial injury among SSc patients is thus probably not due to inflammation. Elevated hs-cTnT might be a marker of abnormal myocardial microcirculation leading to focal myocardial ischemia and finally myocardial fibrosis [36]. The association between ANCA and elevated of hs-cTnT remains uncertain. ANCA would be a marker of either vasculopathy or vasculitis of the myocardial small vessel in SSc patients. Myocardial and/or myocardial vessel biopsy could be helpful for confirmation of the association; however, it is difficult to obtain proof because of the invasive procedure. We suggest performing serial hs-cTnT and long-term clinical follow-up in cases of ANCA positivity in order to determine the progression of cardiac involvement and the development of clinical vasculitis.
Although hs-cTnT was associated with the presence of either p-ANCA or c-ANCA and ESR was associated with the presence of either anti-MPO or anti-PR3, no SSc clinical features or overlap clinical features were found between SSc and systemic vasculitis (i.e., digital ulcer, neuropathy, proteinuria) associated with the presence of ANCA. None of our patients had clinical signs suggestive of systemic vasculitis despite being positive for both P-ANCA and anti-MPO or positive for both c-ANCA and anti-PR3. As in a previous study, ANCA has been reported in SSC patients who had no clinical vasculitis [14]. The SSc patients who had no clinical features of vasculitis were often anti-MPO positive but negative for p-ANCA [14]. Some authors suggested that anti-MPO might be a false positive in SSc or might indicate polyclonal activation, so it might not be a pathologic antibody in 
SSc [14]. As with a previous study, we also found that clinical features such as digital ulcers, glomerulonephritis and myositis were not different between those who were positive and negative for ANCA [34]. Thus, ANCA seems to be a non-specific autoantibody in pure SSC as anti-Ro52 is in SSc [37]. According to our results and the low prevalence of SSc overlap systemic vasculitis [38], ANCA should not be routinely investigated in SSC patients; however, we suggest testing for ANCA in cases of clinically suggestive clinical vasculitis or refractory digital ischemia/ulcer.

All of the patients who had cancer after diagnosis of SSc (4 patients) were negative for ANCA. The ANCA seems to be a protective factor against cancer in SSc but confidence in the statistical analysis was limited because one cell was zero. We suggest a longitudinal follow-up among those who were negative for ANCA. The analysis should also include non-SSc patients who had cancer in order to determine the association between cancer and the presence of ANCA.

Glomerulonephritis is a clinical feature of ANCAassociated vasculitis and it should be differentiated from scleroderma renal crisis, which is a common renal complication in SSc. ANCA-associated glomerulonephritis always has normal renin levels and histopathological findings of the presence of pauci-immune crescentic glomerulonephritis with the absence of vascular changes while the scleroderma renal crisis always has increase of renin level, hypertension and vasculopathy from renal histopathological findings [39]. The patient who was diagnosed with SSc overlap ANCA-associated glomerulonephritis would benefit from treatment with a high dose of steroid and immunosuppressant. Kidney biopsy and testing for ANCA should be performed in SSc patients who have normotensive renal failure. Since none of our patients had clinical features of glomerulonephritis and none of those with proteinuria had undergone kidney biopsy, we cannot be sure whether our patients had occult glomerulonephritis or renal involvement in SSc or not.

Our study had a few limitations. First, no patient was diagnosed with scleroderma-overlap systemic vasculitis, leading to limitations in the power of the statistical analyses. Second, we did not explore the nature of rising serum creatinine by kidney biopsy because the patients had no clinical features of glomerulonephritis, so we could not ascertain the cause of renal impairment in those patients. Third, there were missing data of some clinical features at the onset of the disease; however, there were only a few missing data, so it only slightly affected the statistical analysis. The strengths of our study were: (a) inclusion of the correct number of patients according to sample size calculation, thus validating the prevalence of having SSc and being ANCA positive; and (b) inclusion of parameters of interest, particularly clinical features that might overlap between SSc and systemic vasculitis, cardiac enzyme, and inflammatory markers, revealing the possible role of ANCA testing in SSc. These preliminary data, moreover, have value for evaluating the presence of ANCA in SSc patients and the findings could provide insights into giving patients better care and planning future studies.

In conclusion, around one-fifth of SSc patients have detectible ANCA without any features of vasculitis. The presence of ANCA is associated with inflammation and myocardial injury. ANCA is not antibody specific for vasculitis in SSc. Long-term follow-up is needed to elucidate the clinical implications.

\section{Acknowledgments}

The authors thank (a) the Scleroderma Research Group and the Faculty of Medicine, Khon Kaen University, for support (Grant Number GR60101) and (b) Mr. Bryan Roderick Hamman for assistance with the English-language presentation via Publication Clinic Khon Kaen University, Thailand.

The study received funding support from the Faculty of Medicine, Khon Kaen University, Thailand.

\section{Conflict of interest}

The authors declare no conflict of interest.

\section{References}

1. Silver RM. Clinical aspects of systemic sclerosis (scleroderma). Ann Rheum Dis 1991; 50 Suppl 4: 854-61.

2. Steen VD, Medsger TA Jr. Severe organ involvement in systemic sclerosis with diffuse scleroderma. Arthritis Rheum 2000; 43: 2437-44.

3. Steen V. The heart in systemic sclerosis. Curr Rheumatol Rep 2004; 6: 137-40.

4. Bussone G, Mouthon L. Interstitial lung disease in systemic sclerosis. Autoimmun Rev 2011; 10: 248-55.

5. Cohen S. The gastrointestinal manifestations of scleroderma: pathogenesis and management. Gastroenterology 1980; 79: 155-66.

6. Denton CP, Lapadula G, Mouthon L, Müller-Ladner U. Renal complications and scleroderma renal crisis. Rheumatology (Oxford) 2009; 48 Suppl 3: iii32-5.

7. Liang PK, Clement JM. ANCA-asoociated vasculitis in scleroderma: a case series of fourteen patients. Rheumatology Report 2011: e2. doi:10.4081/rr.2011.e2.

8. Wutzl AL, Foley RN, O'Driscoll BR, Reeve RS, Chisholm R, Herrick AL. Microscopic polyangiitis presenting as pulmonary-renal syndrome in a patient with long-standing diffuse cutaneous systemic sclerosis and antibodies to myeloperoxidase. Arthritis Rheum 2001; 45: 533-6.

9. Dringenberg C, Apenberg S, Andrassy K. p-ANCA with myeloperoxidase antibodies and c-ANCA with protein- 
ase 3 antibodies define a different vasculitis entity in patients with renal involvement. Adv Exp Med Biol 1993; 336: 445-7.

10. Drooger J, Dees A, Swaak AJ. ANCA-positive patients: the influence of PR3 and MPO antibodies on survival rate and the association with clinical and laboratory characteristics. Open Rheumatol J 2009; 3: 14-7.

11. Merkel PA, Polisson RP, Chang Y, Skates SJ, Niles JL. Prevalence of antineutrophil cytoplasmic antibodies in a large inception cohort of patients with connective tis sue disease. Ann Intern Med 1997; 126: 866-73.

12. Caramaschi P, Biasi D, Tonolli E, Carletto A, Bambara LM. Antineutrophil cytoplasmic antibodies in scleroderma patients: first report of a case with anti-proteinase 3 antibodies and review of the literature. Joint Bone Spine 2002; 69: 177-80.

13. Ruffatti A, Sinico RA, Radice A, et al. Autoantibodies to proteinase 3 and myeloperoxidase in systemic sclerosis. J Rheumatol 2002; 29: 918-23.

14. Akimoto S, Ishikawa O, Tamura T, Miyachi Y. Antineutrophil cytoplasmic autoantibodies in patients with systemic sclerosis. Br J Dermatol 1996; 134: 407-10.

15. Endo H, Hosono T, Kondo H. Antineutrophil cytoplasmic autoantibodies in 6 patients with renal failure and systemic sclerosis. J Rheumatol 1994; 21: 864-70.

16. Herrick AL, Oogarah PK, Freemont AJ, Marcuson $R$ Haeney $M$, Jayson MI. Vasculitis in patients with systemic sclerosis and severe digital ischaemia requiring amputation. Ann Rheum Dis 1994; 53: 323-6.

17. Pauzner R, Urowitz M, Gladman D, Gough J. Antineutrophil cytoplasmic antibodies in systemic lupus erythematosus. J Rheumatol 1994; 21: 1670-3.

18. Nässberger L, Sjöholm AG, Jonsson H, Sturfelt G, Akesson A. Autoantibodies against neutrophil cytoplasm components in systemic lupus erythematosus and in hydralazine-induced lupus. Clin Exp Immunol 1990; 81: 380-3.

19. Mustila A, Paimela L, Leirisalo-Repo M, Huhtala H, Miettinen A. Antineutrophil cytoplasmic antibodies in patients with early rheumatoid arthritis: an early marker of progressive erosive disease. Arthritis Rheum 2000; 43: 1371-7.

20. de Bandt M, Meyer O, Haim T, Kahn MF. Antineutrophil cytoplasmic antibodies in rheumatoid arthritis patients. Br J Rheumatol 1996; 35: 38-43.

21. Braun MG, Csernok E, Schmitt WH, Gross WL. Incidence, target antigens, and clinical implications of antineutrophil cytoplasmic antibodies in rheumatoid arthritis. J Rheumatol 1996; 23: 826-30.

22. Röther E, Schochat T, Peter HH. Antineutrophil cytoplasmic antibodies (ANCA) in rheumatoid arthritis: a prospective study. Rheumatol Int 1996; 15: 231-7.

23. Mustila A, Korpela M, Mustonen J, et al. Perinuclear antineutrophil cytoplasmic antibody in rheumatoid arthritis: a marker of severe disease with associated nephropathy. Arthritis Rheum 1997; 40: 710-7.

24. Röther E, Metzger D, Lang B, Melchers I, Peter HH. Antineutrophil cytoplasm antibodies (ANCA) in rheumatoid arthritis: relationship to HLA-DR phenotypes, rheumatoid factor, anti-nuclear antibodies and disease severity. Rheumatol Int 1994; 14: 155-61.

25 . Preliminary criteria for the classification of systemic sclerosis (scleroderma). Subcommittee for scleroderma criteria of the American Rheumatism Association Diagnostic and Therapeutic Criteria Committee. Arthritis Rheum 1980; 23: 581-90.
26. LeRoy EC, Black C, Fleischmajer R, et al. Scleroderma (systemic sclerosis): classification, subsets and pathogenesis. J Rheumatol. 1988; 15: 202-5.

27. Mukerjee D, St George D, Knight C, et al. Echocardiography and pulmonary function as screening tests for pulmonary arterial hypertension in systemic sclerosis. Rheumatology (Oxford) 2004; 43: 461-6.

28. Elixhauser A, Steiner C, Harris DR, Coffey RM. Comorbidity measures for use with administrative data. Med Care 1998; 36: 8-27.

29. Falanga V, Medsger TA. Frequency, levels, and significance of blood eosinophilia in systemic sclerosis, localized scleroderma, and eosinophilic fasciitis. J Am Acad Dermatol 1987; 17: 648-56.

30. WW D. Biostatistics: A Foundation for Analysis in the Health Sciences. $7^{\text {th }}$ edition. John Wiley \& Sons 1999.

31. Derrett-Smith EC, Nihtyanova SI, Harvey J, Salama AD, Denton CP. Revisiting ANCA-associated vasculitis in systemic sclerosis: clinical, serological and immunogenetic factors. Rheumatology (Oxford) 2013; 52: 1824-31.

32. Rho YH, Choi SJ, Lee YH, Ji JD, Song GG. Scleroderma associated with ANCA-associated vasculitis. Rheumatol Int 2006; 26: 369-75.

33. Xu RY, Zhu XF, Yang Y, Ye P. High-sensitive cardiac troponin T. J Geriatr Cardiol 2013; 10: 102-9.

34. Berardi G, De Luca A, Laria M, et al. ANCA positivity in scleroderma patients identifies a poor prognosis: myocarditis and survival. Ann Rheum Dis 2013; 71 (Suppl 3): 399 (Abstract FRI0250).

35. Foocharoen C, Pussadhamma B, Mahakkanukrauh A, Suwannaroj S, Nanagara R. Asymptomatic cardiac involvement in Thai systemic sclerosis: prevalence and clinical correlations with non-cardiac manifestations (preliminary report). Rheumatology (Oxford) 2015; 54: 1616-21.

36. Allanore $\mathrm{Y}$, Meune C. Primary myocardial involvement in systemic sclerosis: evidence for a microvascular origin. Clin Exp Rheumatol 2010; 28 (5 Suppl 62): S48-53.

37. Foocharoen C, Watcharenwong P, Netwijitpan S, Mahakkanukrauh A, Suwannaroj S, Nanagara R. Relevance of clinical and autoantibody profiles in systemic sclerosis among Thais. Int J Rheum Dis 2017; 20: 1572-81.

38. Foocharoen C, Netwijitpan S, Mahakkanukrauh A, Suwannaroj S, Nanagara R. Clinical characteristics of scleroderma overlap syndromes: comparisons with pure scleroderma. Int J Rheum Dis 2016; 19: 913-23.

39. Anders HJ, Wiebecke B, Haedecke C, Sanden S, Combe C, Schlöndorff D. MPO-ANCA-Positive crescentic glomerulonephritis: a distinct entity of scleroderma renal disease? Am J Kidney Dis 1999; 33: e3. 